\title{
Consideration for Fractional Slot Winding of Permanent Magnet Type Synchronous Machine
}

\author{
Yasuhiro MIYAMOTO† \\ Tsuyoshi HIGUCHI $\dagger$, Takashi ABE $\dagger \dagger$
}

\author{
$†$ System Engineering Division YASKAWA ELECTRIC Co. Ltd., Japan \\ Tel: +81-930-23-4151 - Fax: +81-930-23-5162 - e-mail: miya@yaskawa.co.jp \\ $\dagger \dagger$ Department of Electrical and Electronic Engineering, NAGASAKI University, Japan \\ Tel: +81-95-819-2547 - Fax: +81-95-819-2558 - e-mail: thiguchi@nagasaki-u.ac.jp \\ Topics: PM Machines and Drives \\ Key Words: Fractional Slot Winding, Permanent Magnet, Cogging Torque, Motor Constant
}

\begin{abstract}
Fractional Winding is used for permanent magnet type synchronous machine to improve the EMF form and cogging etc. This paper report the characteristics of $\mathrm{q}=1 / 2$ and $\mathrm{q}=3 / 8 \quad(\mathrm{q}<0.5)$ especially. And the mixed coils in each phase winding we called, can give the flexibility of winding design. We report the advantages of this winging method with theory and measured data.
\end{abstract}

\section{INTRODUCTION}

In response to the recent market demands for miniaturization and weight reduction on motors, myriad of permanent magnet synchronous motors of Segmented Core - Concentrated Winding construction have been developed. In particular to the fields of machine tools where abilities to process at high speeds in high accuracies as well as in semiconductor manufacturing equipment industry, there are high demands on further improvements in motor constant $\mathrm{Km}[\mathrm{N}-\mathrm{m} / \sqrt{ } \mathrm{W}]$ and reduction of torque ripple for applications requiring advanced micro-machining and higher process speed capabilities. In the scope of Segmented Core Concentrated Winding structure winding designs where an individual pole/phase slot count " $\mathrm{q}$ " are: $\mathrm{q}=3 / 8$ and $q=3 / 10$ with large flux linkage count $\Psi$ and high cogging frequency characteristics are desirable. However, such Concentrated Winding schemes result in each coil placement of UVW phases consecutively adjacent, and phase group connections become 8-poles and 10-poles per one group where the winding design flexibility can be quite limited.

This paper discusses, evaluates, and reports on experiments of a winding method (Compounded Fractional Slot Winding) that provides improvement on freedom of design for fractional slot winding schemes with reduced coil groups such as $q=3 / 8$ and $q=3 / 10$ where parallel connections of inter-coil-group are not possible.

\section{Advantage S of Compound Fractional Slot WINDIND METHOD}

In our discussions of needs for the Compounded Winding schemes, two types of Fractional Windings below which make the number of slots per pole/phase of " $\mathrm{q} \leqq 1 / 2$ " will be discussed.

\section{(1) Number of slots per pole/phase " $q=1 / 2$ "}

Of the winding methods where high number of coil groups can be achieved is...

- $q=1 / 2$ : (Ex. 6 Poles/9Slots)

Fig. 1 shows (a) a Winding Construction layout, (b) Coil connection diagram, and (c) a Slot Star diagram.

The coil pitch is of $120^{\circ}$ electrical angle, and the Winding Factor $\mathrm{Kw}$ is represented by the Slot Star diagram and the formula (1) below.

【Winding Factor: Kw】

$$
\begin{aligned}
& K w=\frac{2 n \times \cos \left(30^{\circ} \mathrm{r}\right)}{(1+1) n} \quad(\text { for: } \mathrm{r}=1) \\
& K w(1)=\frac{2 \cos 30^{\circ}}{2}=0.866
\end{aligned}
$$

A synchronous motor of 6 Poles/9 Slots would be structured with 3 groups of $q=1 / 2$ ( 2 Poles/3 Slots) as one coil group. Therefore, a maximum of 3 parallel winding connection becomes possible for improved design freedom.

However, as can be seen in Fig.1 above, the magnet motive force vector is 1 and the distribution factor $\mathrm{kd}=1$, so that the harmonic components contained in the winding's permanent magnet flux waveform cannot be effectively reduced. Additionally, the Winding Factor $\mathrm{kw}(1)$ is $\mathrm{kw}(1)=0.866<0.9$ so this cannot be said to be an efficient winding.

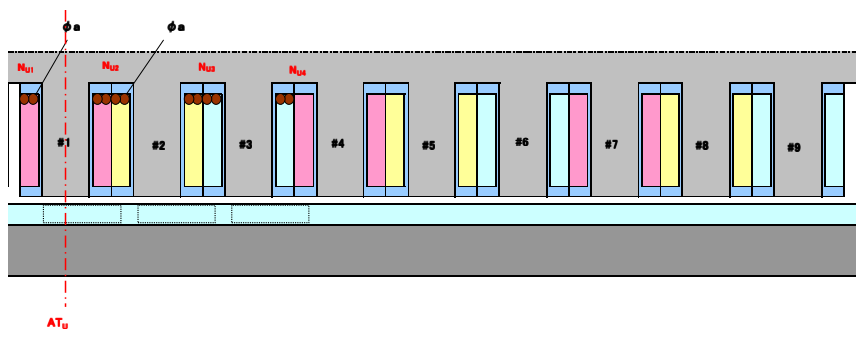

(a) Winding Construction at $\mathrm{q}=1 / 2$ 

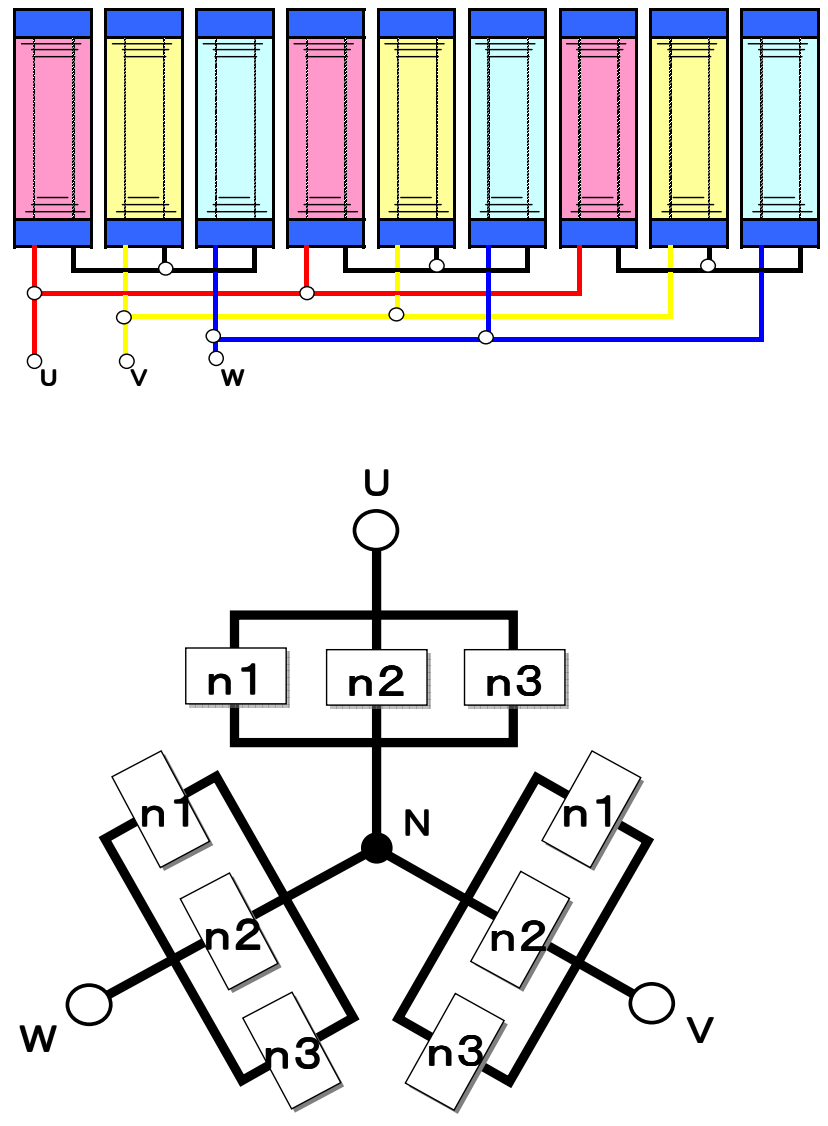

(b) Coil Connection at $\mathrm{q}=1 / 2$

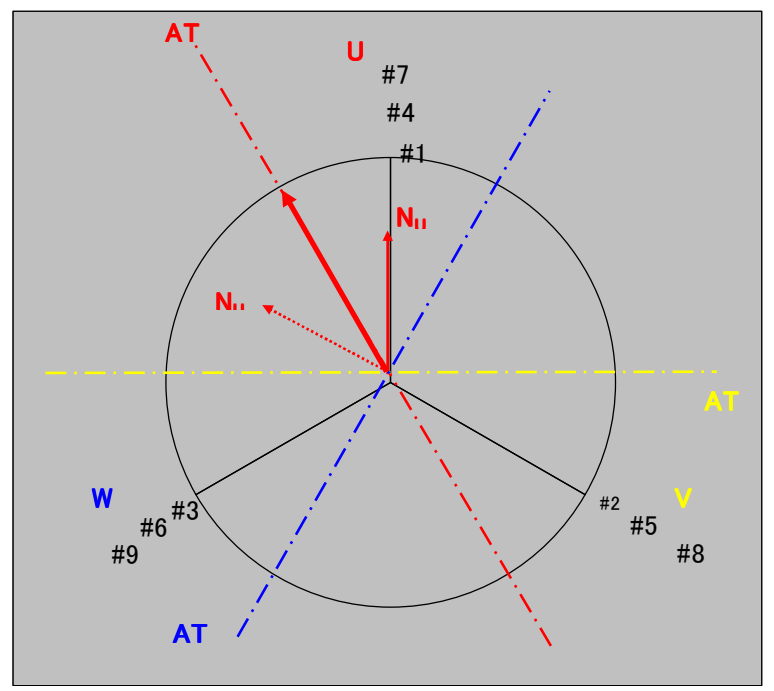

(c) Slot Star Diagram at $\mathrm{q}=1 / 2$

Fig.1. Fractional Slot Winding Method $(\mathrm{q}=1 / 2)$

\section{(2) Number of slots per pole/phase " $q=3 / 8$ "}

One winding scheme, amongst the " $\mathrm{q} \leqq 1 / 2$ " Slots per Pole/Phase windings, with high Winding Factor kw and high cogging frequency fog is the $q=3 / 8$ (Ex. 8 Poles/9 Slots).

Fig.2 (a) is a coil layout diagram, and (b) is a Slot Star Diagram of this winding scheme. The Winding Factor kw obtained from the Slot Star Diagram and the formula (2) will be as follows. In the case of $q=3 / 8$ (Ex.
8 Poles/9 Slots $)$, the slot pitch would be $\theta \mathrm{s}=(2 \pi \cdot 4$ pole pair) $/ 9$ slots $=160^{\circ}$, and if slot vectors are assigned as $\# 1>\# 2>\# 3$ the 9 slots equate to 4 turns (4 pole pair) that can be assigned to the 3 phases as shown on Fig.2 (b). A magnet motive force vector is generated when an electrical current is applied to this slot vector, and the formula (2) can be obtained from the vector distribution.

\section{【Winding Factor: Kw】}

$K w=\frac{n \times \cos \left(30^{\circ}\right)+(1+1) n \times \cos \left(10^{\circ} r\right)+(1+1) n \times \cos \left(10^{\circ} r\right)+n \times \cos \left(30^{\circ} r\right)}{\{1+(1+1)+(1+1)+1\} \mathrm{n}}$

(for: $r=1$ )

$K w(1)=\frac{\cos 30^{\circ}+2 \cos 10^{\circ}+2 \cos 10^{\circ} \times \cos 30^{\circ}}{6}=0.945$

With 8 Poles/9 Slots synchronous motors where one coil group is $\mathrm{q}=3 / 8$ ( 8 Poles/9 Slots), a minimum composition unit will be 8-Poles. Therefore, only one parallel connection is possible with 8 Pole synchronous motors and the design freedom is limited. However, as can be seen on Fig.2 (b), the magnet motive vector distribution is 3 and short-pitch angle is $160^{\circ} / 180^{\circ}$, thus the fundamental Winding Factor kw1 is near 1 as well as the harmonic Winding Factor kwn is small, making possible to reduce the harmonic component contents within the permanent magnet flux waveform of the winding. Especially, by optimizing the magnet widths, it is possible to reduce $5^{\text {th }}$ and $7^{\text {th }}$ harmonic contents that have effects on torque ripples. Furthermore, as mentioned earlier, the cogging frequency fog made higher will mean that absolute value of cogging can be reduced.

As such, the $\mathrm{q}=3 / 8$ winding method has advantages in efficiency and cogging characteristics, but on the other hand has issues in: design freedom limitations (parallel connection not possible), and characteristics not fine tunable under prescribed power supply condition when re-winding an equivalent with different diameter coil wires.

The Table. 1 summarizes the characteristics of $q=1 / 2$ and $\mathrm{q}=3 / 8$.

Winding FactorCharacteristics of fractional winding $q=1 / 2,3 / 8$

\begin{tabular}{|c|c|c|}
\hline $\begin{array}{c}\text { Fractional Slot } \\
\text { Winding }\end{array}$ & $\mathrm{q}=1 / 2$ & $\mathrm{q}=3 / 8$ \\
\hline $\begin{array}{c}\text { Minimum } \\
\text { Composition Unit }\end{array}$ & $\begin{array}{l}2 \text { poles } \\
3 \text { slots }\end{array}$ & $\begin{array}{l}8 \text { poles } \\
9 \text { slots }\end{array}$ \\
\hline $\begin{array}{c}\text { Winding } \\
\text { Design Freedom }\end{array}$ & $\bigcirc$ & $\times$ \\
\hline $\begin{array}{c}\text { Minimum Coil } \\
\text { Number / Group }\end{array}$ & 3 & 8 \\
\hline $\begin{array}{c}\text { Winding } \\
\text { Factor: kw1 }\end{array}$ & $\begin{array}{l}\text { Low } \\
\text { kw1=0.866) }\end{array}$ & $\begin{array}{l}\text { High } \\
(\mathrm{kw} 1=0.945)\end{array}$ \\
\hline $\begin{array}{c}\text { EMF Constant } \\
\text { Waveform Ratio }\end{array}$ & $\triangle$ & $\bigcirc$ \\
\hline Cogging Cycle & 24 & 72 \\
\hline
\end{tabular}



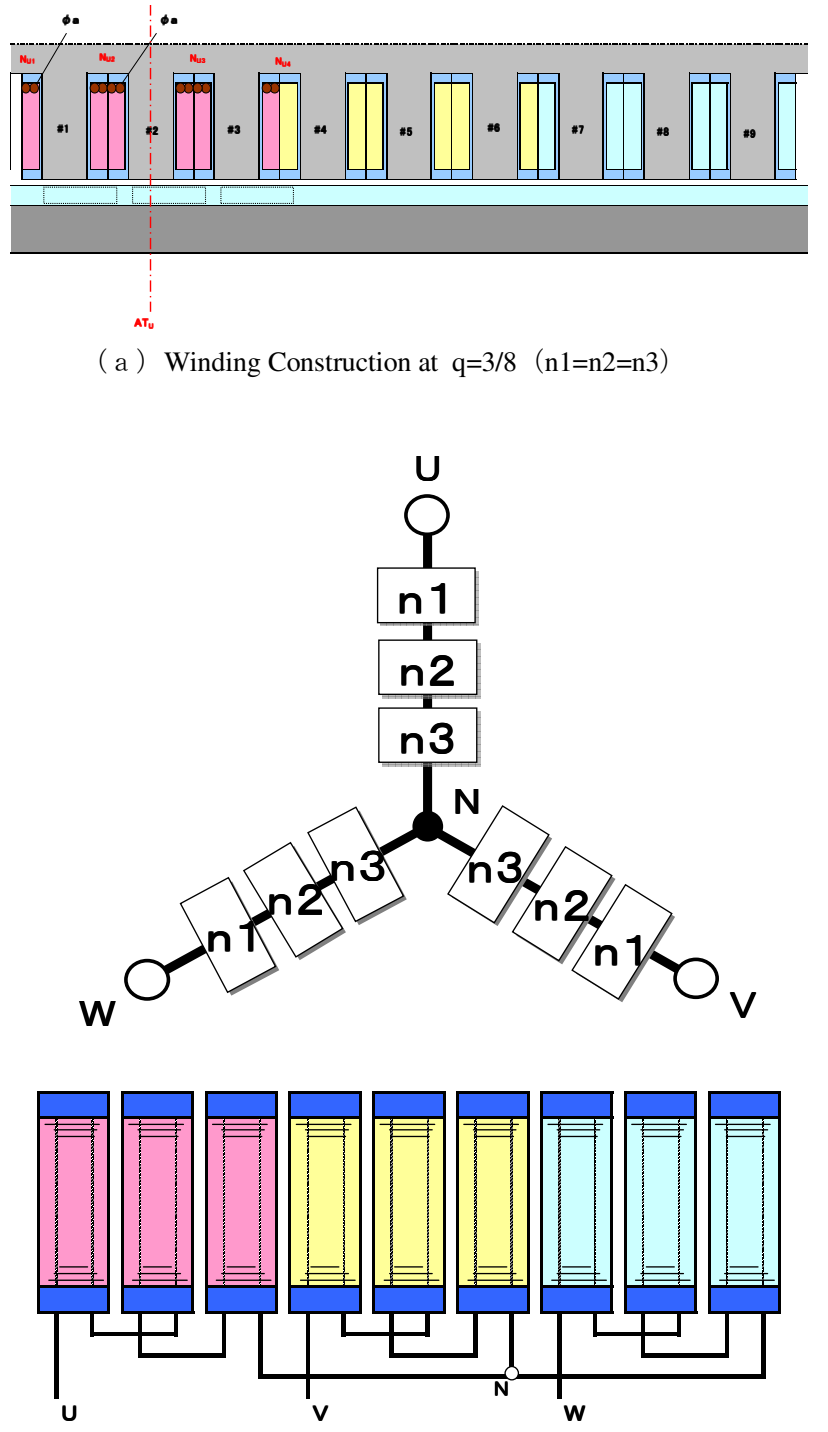

( b ) Coil Connection at $\mathrm{q}=3 / 8$

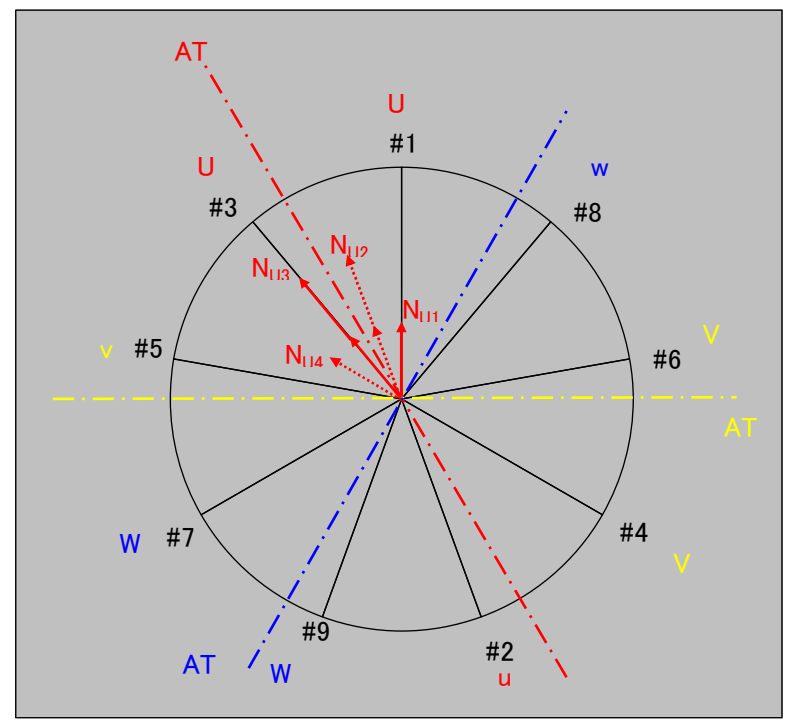

(c) Slot Star Diagram at $q=3 / 8$

Fig.2. Fractional Slot Winding Method $(q=3 / 8)$

\section{OUtline OF COMPOUND Fractional Slot WINDIND METHOD}

The $\mathrm{q}=3 / 8$ winding coil layout shown in the previous section has triple series connected " $3 / \mathrm{q}$ " number of coils in each phase. If all 3 coils are to be wound the same number of turns, the output characteristics had only to be varied by varying the coil wire diameters. Since there are limitations on the multiple stacks that can be wound onto the teeth when attempting to make the slot conductor density equal and dense, the EMF constants of the coils would greatly vary. There is a method of using the same diameter wire with varying number of turns, however, this is not a favorable technique as it would reduce the slot conductor density causing concerns on thermal efficiency. With such given limitations as outlined above, the "Compound Winding" scheme is evaluated. $(\mathrm{JP} 4304999)^{1)} \quad$ There are two cases of Compound Windings as shown below, where the triple series coils are $\mathrm{n} 1, \mathrm{n} 2$, and $\mathrm{n} 3$.

$$
\begin{aligned}
& \mathrm{n} 1=\mathrm{n} 3, \mathrm{n} 1 \neq \mathrm{n} 2,(\mathrm{n} 1=\mathrm{n} 3)>\mathrm{n} 2 \\
& \mathrm{n} 1=\mathrm{n} 3, \mathrm{n} 1 \neq \mathrm{n} 2,(\mathrm{n} 1=\mathrm{n} 3)<\mathrm{n} 2
\end{aligned}
$$

Since the number of winding turns as well as the Winding Factors kw differ between and , magnet widths of each must be evaluated. The details of the winding types and are explained below.

(1) $\mathrm{n} 1=\mathrm{n} 3, \mathrm{n} 1 \neq \mathrm{n} 2,(\mathrm{n} 1=\mathrm{n3})>\mathrm{n} 2$

Winding structure diagram of this method is shown in Fig.3 (a), and a Slot Star Diagram as Fig.3 (b).

This example is for winding ratio...

- $(\mathrm{n} 1=\mathrm{n} 3): \mathrm{n} 2=2.5: 1$ (p.u.)

- Number of turns: $n=6$ (p.u.)

Based on the magnet motive force vector distribution of Slot Star diagram on Fig.3 (b), Winding Factor kw formula will as formula (3).

\section{【Winding Factor: $\mathrm{Kw}$ 】}

$K w=\frac{2.5 n \times \cos \left(30^{\circ}\right)+(2.5+1) n \times \cos \left(10^{\circ} r\right)+(1+2.5) n \times \cos \left(10^{\circ} r\right)+2.5 n \times \cos \left(30^{\circ} r\right)}{\{2.5+(2.5+1)+(1+2.5)+2.5\} \mathrm{n}}$ (for: $r=1$ )

$K w(1)=\frac{2.5 \cos 30^{\circ}+3.5 \cos 10^{\circ}+3.5 \cos 10^{\circ}+2.5 \cos 30^{\circ}}{12}=0.935$

The slot vector distribution diagram would be identical to Fig.2 (c), however, the coils within a phase differ as $(\mathrm{n} 1=\mathrm{n} 3)>\mathrm{n} 2$ and the magnet motive vector distribution will be different. Therefore the fundamental Winding Factor derived from a formula based on the magnet motive vector distribution on Fig. 3 will be $\mathrm{kw}=0.935$. This value is only $-1 \%$ different from the value of $\mathrm{q}=3 / 8(\mathrm{n} 1=\mathrm{n} 2=\mathrm{n} 3)$, and the interlinkage flux $\Psi$ will also be equivalent. In regards to the harmonics Winding Factor kwn, kw5 $=0.01$ and the $7^{\text {th }}$ order will 
have a residual of $\mathrm{kw} 7=0.16$ where the $7^{\text {th }}$ order harmonic component in the EMF can be reduced by measure such as making the magnet width $\mathrm{Wm}=6 / 7 \tau \mathrm{p}$. (See Table.2: Winding Factor Of Each Winding Method)

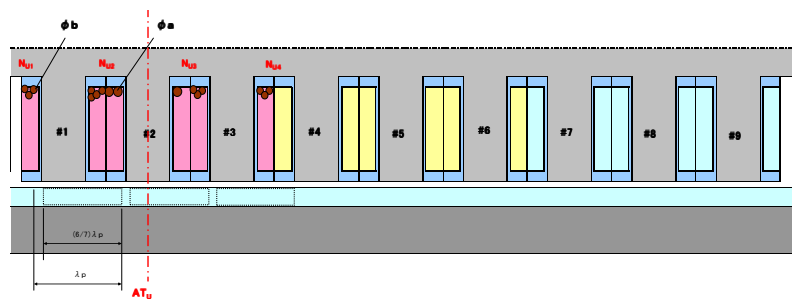

(a) Winding Construction at $\mathrm{q}=3 / 8(\mathrm{n} 1=\mathrm{n} 3)>\mathrm{n} 2$

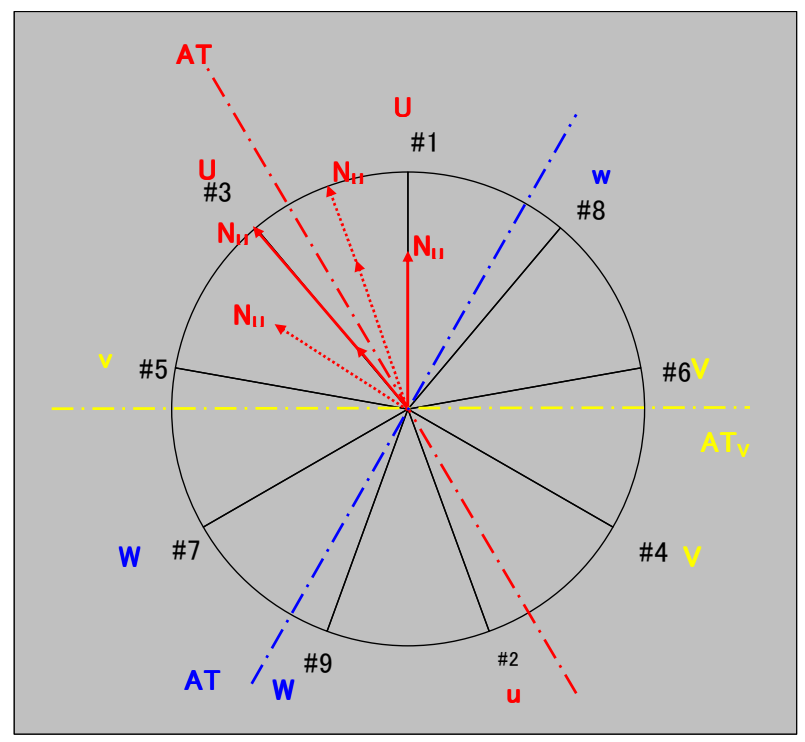

(b) Slot Star Diagram at $\mathrm{q}=3 / 8 \quad(\mathrm{n} 1=\mathrm{n} 3)>\mathrm{n} 2$

Fig.3. Fractional Slot Winding Method $(\mathrm{q}=3 / 8), \quad(\mathrm{n} 1=\mathrm{n} 3)>\mathrm{n} 2$

(2) $n 1=n 3, n 1 \neq n 2,(n 1=n 3)<n 2$

Winding structure diagram of this method is shown in Fig.4 (a), and a Slot Star Diagram as Fig.4 (b).

This example is for winding ratio...

- $(\mathrm{n} 1=\mathrm{n} 3): \mathrm{n} 2=2.5: 1$ (p.u.)

- Number of turns: $n=4.5$ (p.u.)

Based on the magnet motive force vector distribution of Slot Star diagram on Fig.4 (b), Winding Factor kw formula will as formula (4).

\section{【Winding Factor: Kw】}

$K w=\frac{n \times \cos \left(30^{\circ}\right)+(1+2.5) n \times \cos \left(10^{\circ} r\right)+(2.5+1) n \times \cos \left(10^{\circ} r\right)+n \times \cos \left(30^{\circ} r\right)}{\{1+(1+2.5)+(2.5+1)+1\} \mathrm{n} \quad(\text { for: } r=1)}$

$K w(1)=\frac{\cos 30^{\circ}+3.5 \cos 10^{\circ}+3.5 \cos 10^{\circ}+\cos 30^{\circ}}{9}=0.958$
The slot vector distribution diagram would also be identical to Fig.2 (c), however, the coil turns within a phase differ as $(\mathrm{n} 1=\mathrm{n} 3)<\mathrm{n} 2$ and the magnet motive vector distribution will be different from Fig.3 (b) above. The magnet motive vector distribution of Fig.4 (b), in comparison with Fig.3 (b), is shifted towards the magnet motive vector axis The and its fundamental Winding Factor kw (1) will be slightly larger compared to the $\mathrm{q}=3 / 8$ shown in Fig. 2 and Fig.3.

Therefore, the fundamental Winding Factor $\mathrm{kw}=$ 0.958 as based on the formula derived from the magnet motive vector distribution in Fig.4 (b), making value only $+1 \%$ different from the value of general $\mathrm{q}=3 / 8$, and the interlinkage flux $\Psi$ can also be considered as equivalent. In regards to the harmonics Winding Factor kwn, kw5 = 0.308 and the $\mathrm{kw} 7=0.07$, where $5^{\text {th }}$ order will have a residual. The $5^{\text {th }}$ order harmonic component in the EMF can be reduced by measure such as making the magnet width $\mathrm{Wm}=4 / 5 \tau \mathrm{p}$. (See Table.2: Winding Factor Of Each Winding Method)

Further, when comparing the output characteristics as shown on Fig. 5 where $q=3 / 8$ winding $n 1=n 2=n 3$, the total winding turns of Low $\Psi$ winding and High $\Psi$ winding will be:

- Low $\Psi$ Winding: $\mathrm{n}=3(\mathrm{n} 1=\mathrm{n} 2=\mathrm{n} 3=1)$

- High $\Psi$ Winding: $\mathrm{n}=7.5(\mathrm{n} 1=\mathrm{n} 2=\mathrm{n} 3=2.5)$

so it can be understood that the Compound Windings shown in Fig.3 and Fig.4 interpolates the output characteristics of Low $\Psi$ winding and High $\Psi$ winding.

\section{Evaluation of Compound Fractional Slot WINDIND METHOD}

\section{(1) Proof-Of-Concept Machine Specifications}

The proof of concept demonstration units were designed along the concept shown below, based on the previous discussions.

1) Regarding the demonstration units:

The Demonstration Unit $A$ is designed as a Compound Winding $\mathrm{n} 1=\mathrm{n} 3, \mathrm{n} 1 \neq \mathrm{n} 2,(\mathrm{n} 1=\mathrm{n} 3)>\mathrm{n} 2$, where $\mathrm{q}=3 / 8,5^{\text {th }}$ order Winding Factor $\mathrm{kw} 5 \approx 0$, and $7^{\text {th }}$ order Winding Factor kw7 $=-0.161$.

Also, a Demonstration Unit B as $\underline{n 1=n 2=n 3}$ was constructed for the purpose of comparing with the Unit $\mathrm{A}$ in order to confirm the Compound Winding scheme achieves an equivalent basic performance of typical $\mathrm{q}=$ $3 / 8$ scheme.

2) The permanent magnets for the field poles are to be rectangular, and the width $\mathrm{Wm}$ when the pole pitch is $\tau \mathrm{p}$ is determined as " $\mathrm{Wm}=(6 / 7) \tau \mathrm{p}$. The basis of this, when the gap magnetic flux density distribution is assumed to be in a trapezoidal form, its Fourier transformation is shown in Formula(5). In other words, "Wm $=(6 / 7) \tau p$ 
will make the $7^{\text {th }}$ order term $=0$, in order to negate the $7^{\text {th }}$ order harmonics of gap magnetic flux density distribution. (See Fig.6)

$$
\begin{aligned}
\mathrm{Bg}=\frac{4 \mathrm{Bm}}{\pi} & \{\cos (\alpha \cdot \pi / \tau \mathrm{p}) \sin (\mathrm{x} \cdot \pi / \tau \mathrm{p}) \\
& +(1 / 3) \cos (3 \alpha \cdot \pi / \tau \mathrm{p}) \sin (3 x \cdot \pi / \tau \mathrm{p})+ \\
& +(1 / 5) \cos (5 \alpha \cdot \pi / \tau \mathrm{p}) \sin (5 x \cdot \pi / \tau \mathrm{p})+ \\
& +(1 / 7) \cos (7 \alpha \cdot \pi / \tau \mathrm{p}) \sin (7 x \cdot \pi / \tau \mathrm{p})+\cdots \cdot
\end{aligned}
$$

3) A connection PCB is used for the interconnection of each coil winding since the coil wire diameters vary with Compound Windings and continuous winding method cannot be used.

\section{(2) EMF Constant Evaluation}

In this study, EMF constants acquisition and various FFT analyses were performed on the Demonstration Unit $\mathrm{A}$ and $\mathrm{B}$ in order to compare and confirm the differences in Winding Factors where the winding turns within phases vary (for the purpose of reduction in magnetic flux harmonic components), and optimum magnet widths for the various winding methods.

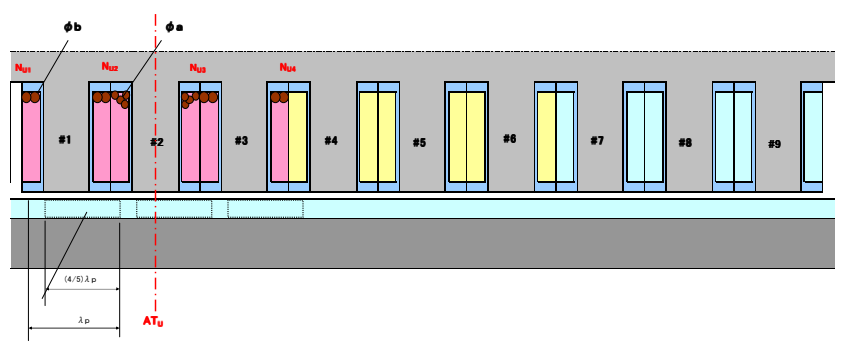

(a ) Winding Construction at $\mathrm{q}=3 / 8(\mathrm{n} 1=\mathrm{n} 3)<\mathrm{n} 2$

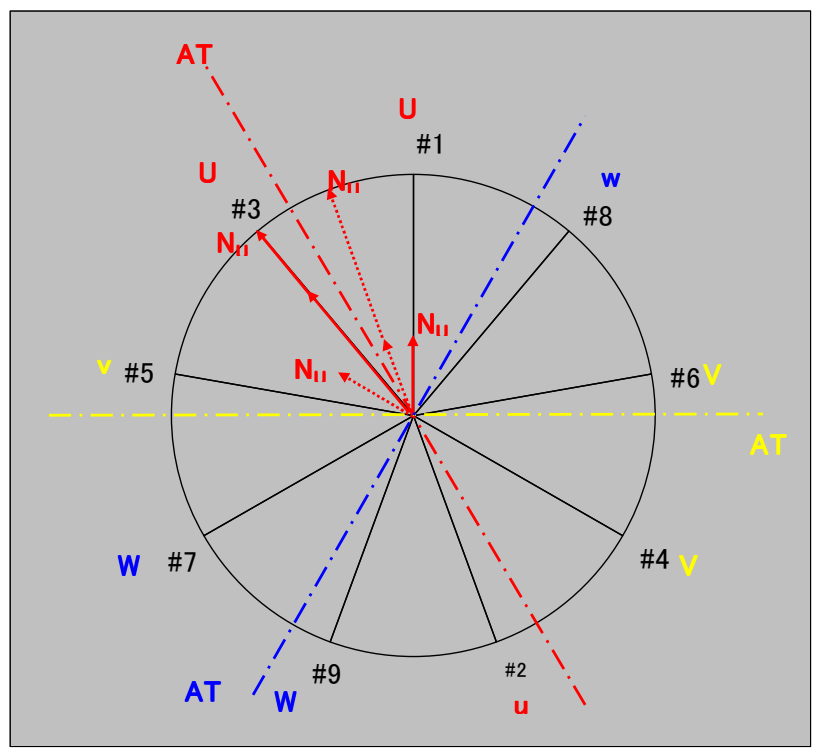

(b) Slot Star Diagram at $q=3 / 8 \quad(n 1=n 3)<n 2$

Fig. 4. Fractional Slot Winding Method $(\mathrm{q}=3 / 8), \quad(\mathrm{n} 1=\mathrm{n} 3)<\mathrm{n} 2$

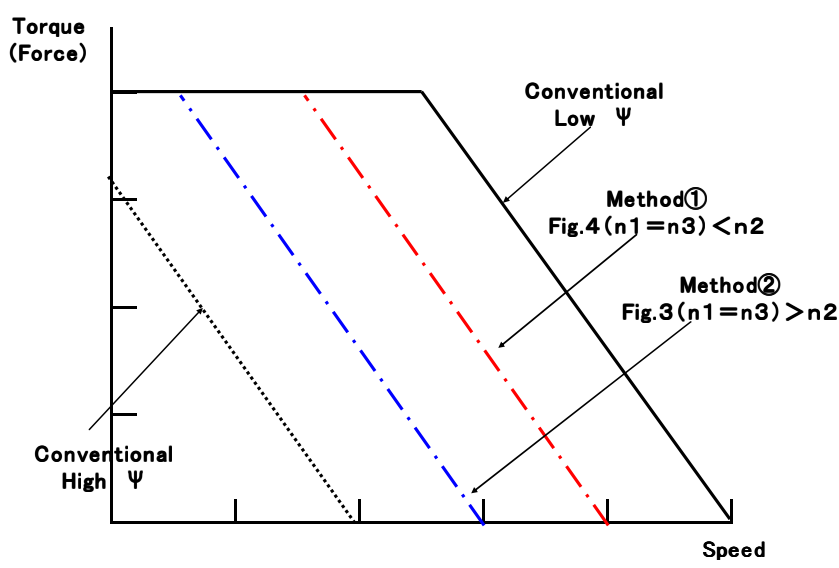

\begin{tabular}{|c|c|c|c|c|}
\hline \multirow[t]{2}{*}{ q } & \multirow[t]{2}{*}{$q=1 / 2$} & $q=3 / 8$ & \multicolumn{2}{|c|}{$q=3 / 8$ (Mixed Winding) } \\
\hline & & High $\Psi$ & $(n 1=n 3)>n 2$ & $(n 1=n 3)<n 2$ \\
\hline Order: $r$ & Kw & $\mathrm{Kw}$ & Kw & Kw \\
\hline 1 & 0.866 & 0.945 & 0.935 & 0.958 \\
\hline 3 & 0.000 & 0.578 & 0.506 & 74 \\
\hline 5 & -0.866 & 0.140 & 0.015 & 0.308 \\
\hline 7 & -0.866 & -0.061 & -0.161 & 0.074 \\
\hline 9 & 0.000 & 0.000 & -0.001 & 0.000 \\
\hline 11 & 0.866 & 0.061 & 0.161 & -0.073 \\
\hline 13 & 0.866 & -0.139 & -0.013 & -0.306 \\
\hline 15 & 0.000 & -0.576 & -0.503 & -0.672 \\
\hline 17 & -0.866 & -0.944 & -0.934 & -0.958 \\
\hline 19 & -0.866 & -0.946 & -0.937 & -0.959 \\
\hline 21 & 0.000 & -0.580 & -0.508 & -0.676 \\
\hline
\end{tabular}

Fig.5. "Speed-Torque(Thrust Force)" Characteristics of each winding method.

Table 2. Winding factor of each winding method

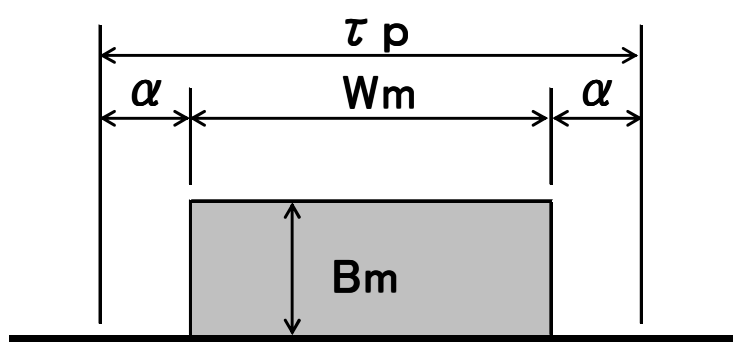

Fig.6. Gap flux density made by block magnet shape.

\section{CONClusions}

Conclusions of this study are as summarized below.

(1) Though the flexibility in designs is limited, the $\mathrm{q}=3 / 8$ winding method is largely effective in improving the EMF form factor ratio.

(2)With the $q=3 / 8$ winding method, use of the compounded winding method where the coils within a phase are wound with different number of turns would result in winding design flexibility (number of winding turns).

(3) With the $q=3 / 8$ compounded winding method, the $5^{\text {th }}$ and $7^{\text {th }}$ order harmonics Winding Factor kw5 and kw7 will vary depending on various winding combinations. 
Therefore, the permanent magnet form factor (magnet width $\mathrm{Wm}$ ) can be optimized to further proximate the EMF constant waveform to sine wave form.

As seen above, effectiveness of the Compounded Winding Method was confirmed, and the validity of this proposal has been confirmed.

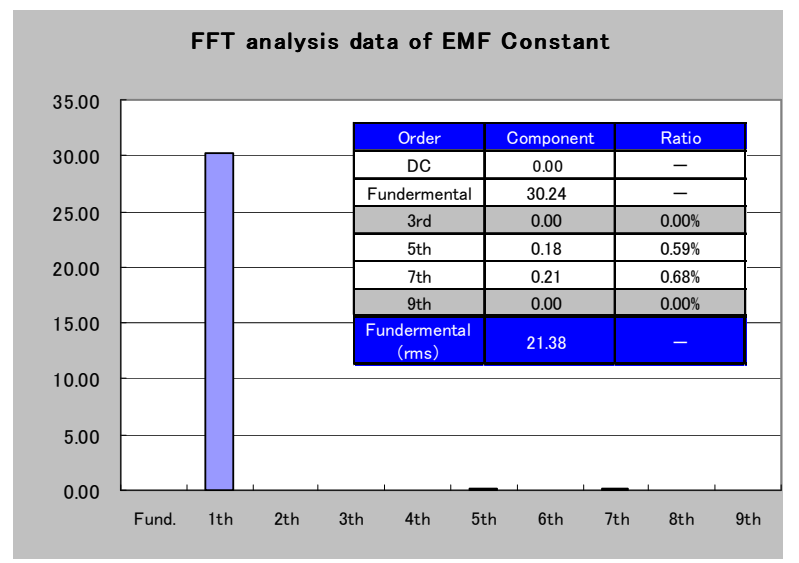

(a) Demonstration Motor: A

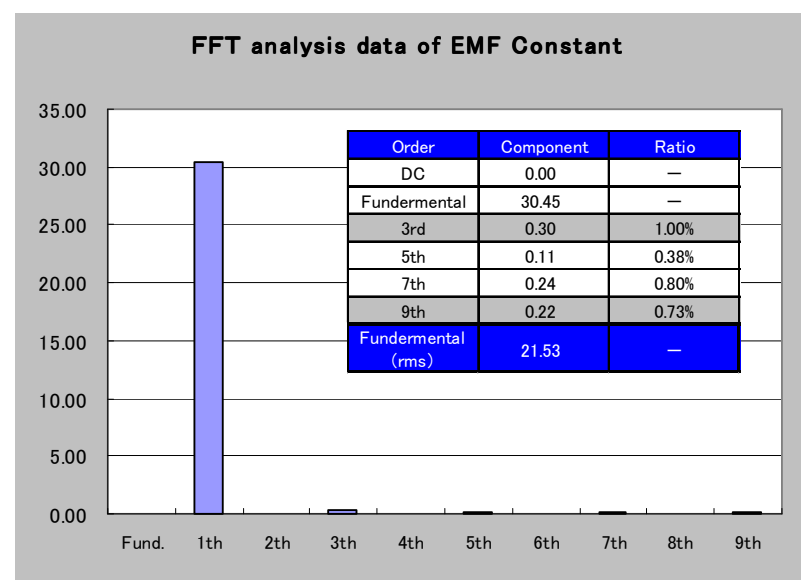

(b) Demonstration Motor: B

Fig.7. Measured EMF constant data

\section{REFERENCES}

1) MIYAMOTO, TANABE, KAWAHARA :

3 Phase Armature winding for the motor,

Japanese patent : No. JP430499 (2009)

2) IWANE SHIGYO : Electric Machines Design Theory( I )

Maruzen Publishing Company (1950) p $224-$ p 232, 「2.5.3.1

Fractional Slot Winding $\rfloor$

3) IWANE SHIGYO : Electric Machines Design Theory( I )

Maruzen Publishing Company (1950)

p 210- p 216,

$\lceil 2.5 .1$ Induced Voltage of Armature Winding Coil $\rfloor$ 